\title{
The Value of Traditional Rural Landscape and Nature Protected Areas in Tourism Demand: A Study on Agritourists' Preferences
}

\author{
Biancamaria Torquati ${ }_{1}^{*}$, Tiziano Tempesta2, Daniel Vecchiato2, Sonia Venanzi ${ }_{1}$, Chiara \\ Paffarini 1
}

1 University of Perugia, Department of Agricultural, Food and Environmental Sciences, Borgo XX Giugno 74; 06121, Perugia, Italy 2 University of Padua, Department Land, Environment, Agriculture and Forestry, Via dell'Università 16; 35020, Legnaro (PD), Italy

\begin{abstract}
This study focuses on how traditional rural landscape and proximity to a Natura 2000 Site of Community Importance ( $\mathrm{SCl}$ ) might influence consumers' choice of an agritourism farm for a weekend stay. Data were collected in Umbria region's (Italy) agritourism farms in 2014 by interviewing 160 tourists. Results from a discrete choice experiment reveal that the most important feature affecting the interviewees' propensity to pay a premium price to stay in an agritourism farm is the well-preserved traditional landscape (willingness to pay $32.32 € /$ night for two people), followed by the availability of a swimming pool (willingness to pay $20.95 € /$ night for two people), the proximity to a historical village (willingness to pay $18.37 € /$ night for two people) and, the location in a Natura $2000 \mathrm{SCl}$ (willingness to pay $13.57 € /$ night for two people). Furthermore, the results underline how the preservation of the traditional landscape and protection of the surrounding environment play a strategic role in developing agritourism and provide economic benefits to local communities.
\end{abstract}

\section{Keywords:}

traditional rural landscape; Natura 2000 sites; biodiversity; agritourism; discrete choice experiments; Italy

\footnotetext{
*Corresponding author. Email: bianca.torquati@unipg.it
}

(C) The Authors. 2017. Landscape Online. This is an Open Access article distributed under the terms of the Creative Commons Attribution License (http://creativecommons.org/licenses/by/4.0), which permits unrestricted use, distribution, and reproduction in any medium, provided the original work is properly cited. 


\section{Introduction}

$\mathrm{T}_{\mathrm{t} \text { he }}^{\mathrm{h}}$ he aim of this study is to verify whether the traditional rural landscape and the environmental context in which an agritourism farm is located can influence the price consumers are willing to pay for a weekend stay in Umbria region, Italy. This is of particular relevance since agritourism ${ }^{1}$ farms can constitute a significant factor in the economic development of less favoured rural areas (Skuras et al. 2006; Slee et al. 1997) and contribute to the diversification of farming income (Randelli et al. 2014).

Agritourism farms have been providing different services, such as taking part in an agricultural process, hospitality, recreational and leisure activities, and catering, since the last century (Santeramo \& Barbieri 2016; Tew \& Barbieri 2012). Therefore, an agritourism, contrary to tourism operators, has a strict linkage with its surrounding landscape and environment and can contribute to its maintenance and improvement.

In Italy, agritourism was born somewhat spontaneously in the seventies as a form of hospitality, becoming widespread throughout the country, especially in recent decades (Busby \& Rendle 2000; Ohe \& Ciani 2011; Santucci 2013). In 2013, there were about 20,000 agritourism farms (2.4\% of Italian farms), accounting for $4.9 \%$ of the total number of beds in the Italian hospitality sector. In the ten-year period of 2003-2013, the sector showed an overall $60 \%$ growth in term of the number of agritourism farms (ISTAT 2014). Italian agritourism farms are chosen as touristic destinations by 5 million tourists every year, and, similar to other touristic destinations, we assume that the choice of an agritourism depends on push and pull factors (Kim \& Lee 2002; Yoon \& Uysal 2005). As stated by Devesa et al. (2010 p. 547), "Push factors are more

1 According to Italian law (L. 96/2006), agritourism means "accommodation and hospitality activities carried out by farmers and their family members connected with the main activities of cultivation, forestry, and breeding". related to internal or emotional aspects, such as the desire for escape, rest and relaxation, adventure, or social interaction. Pull factors are linked to external, situational, or cognitive aspects, of which, attributes of the chosen destination, leisure infrastructure and cultural or natural features are examples". These factors influence the motivations that encourage a tourist to reach a given holiday location. The discrepancy between motivations and actual touristic experience determines the visitor's loyalty to that destination, that is, the degree of satisfaction and the probability that the tourist will return or recommend it to others (Park \& Yoon 2009; Yoon \& Uysal 2005).

For the promotion and development of agritourism, it is important to understand which factors motivate people to choose certain touristic destinations.

Many studies indicate that key pull factors for many touristic activities are the characteristics of the environment and landscape (Bel et al. 2015; Devesa et al. 2010; Gao et al. 2014; Hedlund 2013; Lee et al. 2010; Macagno et al. 2010; Paracchini et al. 2015). Other studies look at how tourism is influenced by the biodiversity in Natura $2000 \mathrm{SCls}^{2}$ (Gantioler et al. 2014; Macagno et al. 2009). Macagno et al. (2009) show that most of the biodiversity and landscape indicators included in the analysis are statistically significant in determining tourists' choices and visit length.

Therefore, while there may be numerous factors that motivate tourists to choose rural areas, the opportunity to visit well-conserved landscapes and uncontaminated natural areas plays an important role (Carpio et al. 2008; Flanigan et al. 2015; Fleischer \& Tchetchik 2005; Gao et al. 2014; Sidali \& Schulze 2010;

\footnotetext{
2 Natura 2000 Site of Community Importance (SCI) is a network of nature-protected areas in the European Union. It includes Special Areas of Conservation (SACS, defined by the Habitats Directive) and Special Protection Areas (SPAs, designated under the Birds Directive). The Habitats Directive requires $\mathrm{SCls}$, which, upon the agreement of the European Commission, become SACs to be designated for species other than birds and for habitat types (e.g., types of forests, grasslands, wetlands, etc.) (https://www.eea.europa.eu/dataand-maps/data/natura-8, last access 06 November 2017)
} 
Walford 2001). Among landscapes, the traditional rural ones are of particular interest because of their historical and cultural value and their beauty giving the area unique characteristics and identity (Agnoletti 2013; Antrop 2005; Claval 2005; Howley et al. 2012; Torquati et al. 2015). In fact, traditional rural landscapes are the result of adapting cultivation techniques to the particular environmental and the social and cultural characteristics of a given area, and, therefore, present a high degree of uniqueness, which can improve the touristic brand of an area (Lim \& Weaver 2014; Ohe \& Kurihara 2013). Rural tourism depending on the quality of the landscape and the environment implies certain challenges for its development in an area. From an economic point of view, in rural areas, the quality of landscape is a positive (or negative) externality and a joint product of farming (Abler 2004; Yadav et al. 2013). In fact, while farmers do not have intrinsic economic motivation for preserving and enhancing the landscape's beauty and biodiversity, they are the primary contributors to these characteristics in a given area (Abler 2004). The tourists, as well as the touristic operators, benefit from the externalities produced by the primary sector. In the absence of some form of compensation from the beneficiaries to the producers of the rural landscape and environmental quality, the degradation phenomena of the rural landscape could negatively impact rural tourism (Abler 2004; Bastian et al. 2015).

Consequently, agritourism could be a vehicle by which farms could internalize the benefits derived from the production of the rural landscape and environmental externalities.

Spending a vacation on an agritourism farm, tourists have the possibility to experience the quality of the farm, rural landscape, and the environment much more directly than through rural tourism (Fleischer \& Tchetchik 2005; Leco et al. 2013), as they have direct contact with the farm's activities and their environment. Hence, agritourism farms might devote greater attention to rural landscape, and environment quality (Gao et al. 2014). However, for agritourism to become a vehicle of landscape and environment conservation, guests might be willing to pay a premium price for agritourism destinations in prized rural landscapes or areas of naturalistic interest contributing to their conservation.

Few studies have verified the existence of a link between the quality of the landscape and environment, and the benefits enjoyed by agritourism farms concerning increased demand (Gao et al. 2014).

Some researchers have investigated the demand characteristics of Italian agritourism in comparison with the national and international tourism demand in general (Ohe \& Ciani 2012); Santeramo (2015) and Santeramo and Morelli (2014) have analysed the characteristics of international demand for Italian agritourism. Other researchers have examined the profitability of running an agritourism (Barbieri \& Mshenga 2008; Koutsouris et al. 2014; LaPan \& Barbieri 2014; Schilling et al. 2014; Tew \& Barbieri 2012). These scholars have rarely considered the relationship between the agritourism accommodation price and the quality of the surrounding landscape and environment. .

The study of this relationship has been deepened only in few works. According to Fleischer and Tchetchik (2005), Fleischer and Tsur (2000), Vanslembrouck et al. (2005), the agricultural landscape positively affects the price of agritourism accommodation. Implementing the hedonic price model, Fleischer and Tchetchik (2005) and Vanslembrouck et al. (2005) found that the agritourism owner can charge a higher accommodation price due to agricultural amenities located in the area. Agricultural landscape as attribute gives a positive willingness to pay (WTP), both in Fleischer and Tchetchik (2005) in terms of landscape amenities within agriculture and in Vanslembrouck et al. (2005) in terms of agricultural activities determining landscape. These results confirm those obtained by Fleischer and Tsur (2000), which used the travel cost methodology.

The aim of this study is to examine agritourism guests' preference for tangible and intangible services of agritourism and measure the importance the visitors assign to these factors in the Umbria Region, which together with Tuscany, has been 
important in the history of agritourism, providing models for its global spread. Specifically, this study aims at understanding how two territorial factors, as traditional rural landscape and proximity to a Natura 2000 Site with high level of biodiversity, might influence tourism consumers' choice for a weekend stay at an agritourism.

To the best of our knowledge, no other studies focused on the valuation of the competitive advantage that can be derived from territorial factors for rural tourism in monetary terms applying Discrete Choice Experiment (DCE) and using as a vehicle of payment an overnight stay price ${ }^{3}$ in an agritourism. The results of this study advance knowledge on the role of territorial factors in determining tourism consumer behaviour and providing a competitive advantage for agritourism farms that offer hospitality in SCls, where biodiversity conservation is guaranteed, and a high quality of the traditional rural landscape. It also points out that rigorous land management through agritourism activities could be a win-win situation for sustainable land use and increase farming income.

\section{Methodology}

\subsection{Attributes and experimental design of the study}

The Discrete Choice Experiments (DCE) approach is a particularly useful method as it allows the assessment of the role of each individual attribute in identifying people's WTP rather than the WTP for a

\footnotetext{
3 The readers interested in a broader review on alternative valuation methods should refer to, among others, Santeramo and Barbieri (2016), Capriello et al. (2013), and Contini et al. (2009). Crouch and Louviere (2000) review the literature from the late 1990s on the application of Conjoint Analysis (CA) and Discrete Choice Experiments (DCE) to the tourism sector, and found that 19 studies were conducted using DCEs and 16 using CA; they also report nine studies that analyse the determinants of tourism destination choice, eight of restaurant choice, six of recreational activities, and five of hotel choice. Recent studies applied DCE to analyse the demand for hotel stays (Adhikari 2015) and rural houses that offer certain specific services (Albaladejo-Pina \& Díaz-Delfa, 2009).
}

package of attributes represented in a given tourism product or development project (Barros et al.2008; Choi et al.2010; Kelly et al.2007; Lindberg \& Veisten 2012). Accordingly, the DCE model results can be used to estimate how changes in attribute levels affect market demand as well as consumer WTP. In fact, following Lancaster's demand theory (1966), consumers derive more utility from a good in terms of its characteristics than from the good per se.

A typical DCE relies on a questionnaire, where a hypothetical market with several sets of choices is presented at the respondent and the answerer being asked for choosing the preferred option among those available. The hypothetical market is based on a well-defined good or service, and each set of choices typically presents the same good/service diversified in some of its main features (technically called attributes). Each characteristic is defined by its levels. The DCE was designed considering six attributes selected analysing previous studies in this field of research (Albaladejo-Pina \& Díaz-Delfa 2009; Apostolakis \& Jaffry 2005; Bastian et al. 2015; Brau 2008; Gao et al. 2014; Huybers \& Bennett 2003; Ohe \& Ciani, 2011; Juutinen et al. 2011; Macagno et al. 2010; Sidali \& Schulze 2010; Yadav et al. 2013). Three attributes were related to the territory characteristics of the agritourism farm: rural landscape quality, nature quality and the distance from a historical village.

The rural landscape quality indicates whether the traditional rural landscape is well preserved or not; the nature quality states whether the biodiversity is preserved by a Natura $2000 \mathrm{SCl}$ or not, and the distance from a historical village is a proxy to evaluate if the village is within a walking distance to the agritourism. Two attributes were related to the agritourism features, those identified as facility based services by Ohe and Ciani (2011), respectively, the number of spikes as a proxy for overall hospitality quality assessing (the number of spikes is similar to the number of stars for hotels) and the availability of a swimming pool. The price attribute (for an overnight stay in a double room in the summer) was chosen to derive monetary measures of WTP. A preliminary version of the questionnaire was discussed during a focus group that took place in June 2014. 
While other attributes are quite intuitive, the meaning of rural landscape quality deserves an accurate definition in the DCEs' preamble, where the choice scenario was presented to respondents. In the DCE scenario introduction, we drew upon Antrop's delineation of a "well preserved traditional rural landscape": "It contains the complex history of a place or region, which still can be read from its composition and structure" (Antrop 2005 p. 25).

Each attribute had two levels: the number of spikes (three or five, according to Regional Law $\mathrm{n}$. $28 / 1997$ in Umbria, where five is the maximum number of spikes) for certifying agritourism quality; presence/absence of the Natura $2000 \mathrm{SCl}$ where biodiversity conservation is guaranteed; presence/ absence of the high quality of the rural landscape in the agritourism location (characterized by the well-preserved traditional rural landscape or not); presence/absence of a swimming pool; a distance longer or shorter than three kilometres from a historical village. Four levels were chosen for the prices (70€; 90€; 110€; 130€).

The experimental design was generated with Ngene ${ }^{\circledR}$ software. We opted for an unlabelled Dp-efficient design, namely a D-efficient design in which priors were used.

The priors were obtained from a preliminary submission of the questionnaire to a random sample of 20 respondents. In the choice experiment, eight choice sets to each respondent were proposed. In each set, the respondent had to choose between two potentials "agritourism farm" proposals (scenarios) or the "none of these" (opt-out) option.

Data were analysed with a random parameter logit model (RPL) (McFadden 1974; Train 2003; Train \& Weeks 2005). An advantage of RPL models is that they consider sample heterogeneity treating it in a continuous fashion and allow the estimation of the individual WTP for each attribute investigated. The RLP model examined along with DCE attributes both socio-economic characteristics and motivational aspects of respondents in choosing an agritourism.

To take into account the effects of individual characteristics on the demand for the agritourism accommodation, we interacted each attribute with a set of potential predictors, the socio-economics characteristics and personal motivations that undergo the choice of an agritourism destination, specifically. Concerning the socio-economics characteristics using an iterative process, we selected those features that were significantly correlated to the agritourism attributes and significant at least at the $90 \%$ level (educational level = graduate; income medium-high or high; age lower or equal to 30 years). These attributes confirmed Carpio et al. (2008) findings about average farm visitors characteristics.

Regarding the motivations underlying the choice of an agritourism holiday, the interviewees were asked for rating the importance of 10 elements according to a five-point Likert scale (from not relevant at all to highly relevant).

Starting from these answers, we performed a k-means cluster analysis on respondents estimated with the SPSS statistics package version 11.The k-means cluster analysis procedure allowed us to group the interviewees into two clusters. A dummy variable referring to the respondents that belong to the second cluster was interacted with the agritourism's attributes in the utility function used in the RPL model. The following interactions were then used in the DCE utility function (Eq. 1):

- Distance from a historical village lower than $3 \mathrm{~km} \times$ educational level $=$ graduate

- $\mathrm{SCl} x$ income medium-high or high

- $\mathrm{SCl} \times$ cluster 2

- Presence of a swimming pool $x$ age less or equal to 30 years

- Presence of a swimming $x$ cluster 2

- Presence of a swimming $\mathrm{x}$ education level $=$ graduate

They resulted significant at least at the $90 \%$ level in the RPL model. In the case of the landscape quality and the five spikes, it was not possible to find any significant interaction term. Moreover, the coefficient of the five-spike attribute was not heterogeneous, according to the RPL model results, meaning that there does not exist a significant degree of variability among the individual preferences. 
As usual in RPL models' estimation, price and optout were treated as non-random parameters (Hole \& Kolstad 2012). The other attributes were considered normally distributed.

The models were estimated with NLogit $4^{\circledR}$, applying the following additive and linear indirect utility function:

$$
\begin{aligned}
U\left(X_{i}\right)= & \beta_{\text {optout }} \cdot \text { Opt }- \text { out }+\sum_{i=1}^{5} \beta_{i} \cdot Y_{i} \\
& +\sum_{i=6}^{11} \beta_{i} \cdot Z_{i}+\beta_{\text {price }} \cdot \text { Price }
\end{aligned}
$$

where Opt-Out is a dummy assuming value 1 if the choice task option is the opt-out, and 0 otherwise; $\mathrm{Yi}$ is a vector of dummy variables representing the following attribute levels: Spikes 5, SCl, High quality landscape, Swimming pool; $Z_{\mathrm{i}}$ is a vector representing the dummies for the following interaction terms: Low Village Distance high education, $\mathrm{SCl}$ income, $\mathrm{SCl}$ cluster2, $\mathrm{SCl}$ high education, Swimming pool. age, Swimming pool cluster2. Price is a continuous variable that indicates the price for an overnight stay for two people.

More in depth, Spikes 5 is a dummy indicating if the proposed agritourism farm is classified with five spikes; $\mathrm{SCl}$ is a dummy that indicates that the agritourism farm is in an $\mathrm{SCl}$ area; High quality landscape is a dummy that assumes value 1 if the agritourism is characterized by high landscape quality; Swimming pool is a dummy that indicates whether the agritourism farm has a swimming pool; Low village distance is a dummy that assumes value 1 if the agritourism is in a range of less than $3 \mathrm{~km}$ from the closest historical village; high education is a dummy that indicates that the respondent education level is graduate; cluster 2 is a dummy that indicates that the respondent belongs to cluster 2 according to the k-means cluster analysis; income is a dummy that indicates that the respondent has a mediumhigh income; age is a dummy that indicates that the age of the respondent is lower than or equal to 30 .

It is possible to estimate the average WTP for each attribute level as follows:

$$
\mathbf{W T P i}=-\boldsymbol{\beta}_{\mathrm{i}} / \boldsymbol{\beta}_{\text {price }}
$$

where $\beta_{i}$ is the estimated coefficient of any attribute level except price.
Given that RPL models make it possible to estimate not only the mean WTP of the sample but also the individual WTP for the attributes considered in the model, we calculated the number of people willing to pay a given amount, looking at the complementary cumulative frequencies of individual WTPs for random parameters. This calculation allowed us to provide a more accurate analysis of the demand for each random attribute. For nonrandom parameters, specifically parameters that do not present heterogeneity among respondents, we could not perform any further analysis on preference distributions but had to rely on mean estimates (Hensher \& Greene 2003).

\subsection{Questionnaire structure}

The questionnaire consisted of an introductory part and three sections. The opening part presented the survey, and a box insert summarised the research topic. Interviewees were provided with some information about the meaning of the traditional rural landscape and the conservation of biodiversity in Natura 2000 SCls.

The first section gathered information about the respondents' experiences with agritourism holidays.

The second part focused on the choice experiment. After introducing the hypothetical scenario, each interviewee measured eight choice tasks whose an example is presented in Fig.1. The last section of the questionnaire collected socio-economic information about the respondents.

\subsection{Data collection site and procedures}

Data were gathered in situ in August 2014 from faceto-face interviews with 160 guests of the agritourism farms.

A preliminary inquiry into the existence of such structures near the $\mathrm{SCl}$ selected for the study was conducted to choose the agritourism farms. According to the official statistics (ISTAT 2014), in the Umbria Region, there were 1,268 authorized agritourism farms offering accommodation services (apartments or bedrooms), spread over an area of 


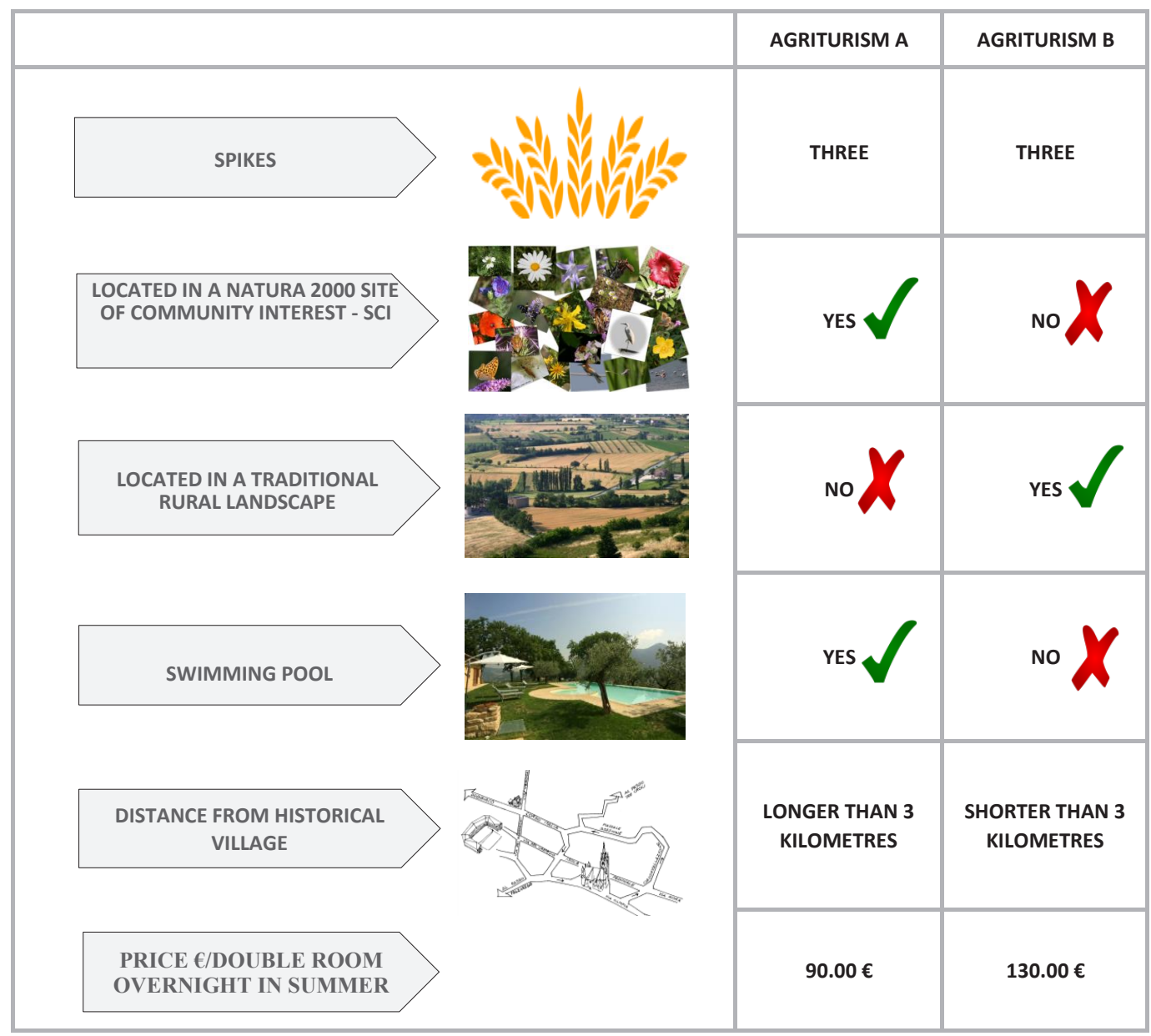

Figure 1: An example of choice task

8,456 square kilometres, $16 \%$ of which included in $106 \mathrm{SCls}$.

Firstly, we selected three Natura $2000 \mathrm{SCls}$ (Fig. 2): Ansa degli Ornari in the district of Perugia (photo A); Bosco Sereni and Torricella in the municipality of Perugia and Marsciano (photo B); and Piani di Castelluccio in the area of Norcia (photo C).

The choice was based on the size of the $\mathrm{SCl}$ (limited, average, and large), the presence of well-preserved traditional rural landscapes, and how well these sites represented the region's range of agritourism farms. Each of these areas has interesting characteristics for tourism and leisure activities related to the aspects of the location's landscape.

The "Piani di Castelluccio" of Norcia in the Valnerina area is a plateau included in the National Park of Monti Sibillini, and it has been classified as a historical rural landscape (Agnoletti, 2013). The area is characterised by the small-scale and temporary

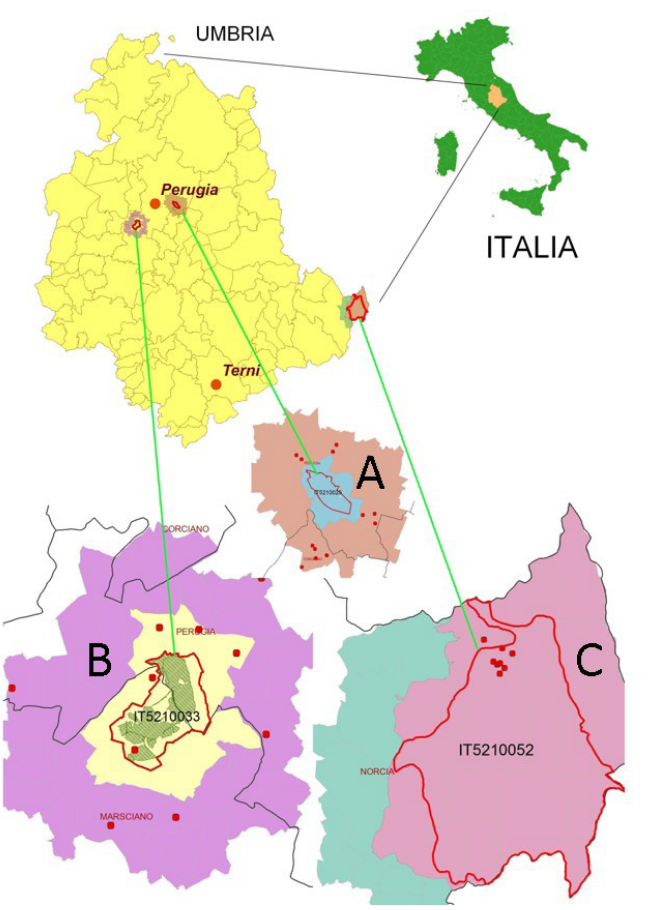

Figure 2: Study area - Geographic location of the SCls selected 


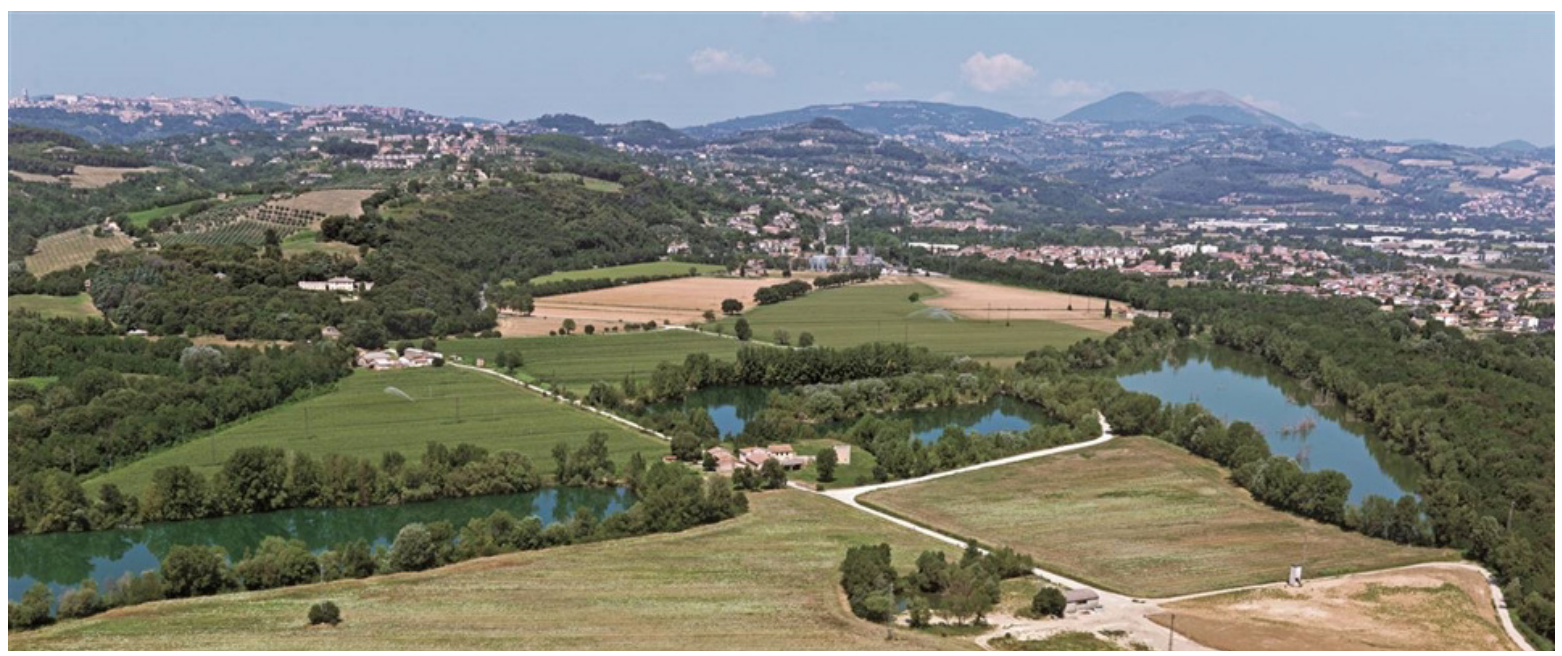

Photo Study Area A: Ansa degli Ornari (http://www.umbriapaesaggio.regione.umbria.it/media/ scopri-lumbria-dallalto-volo-5. Picture 28, last Access 06.11.2017)

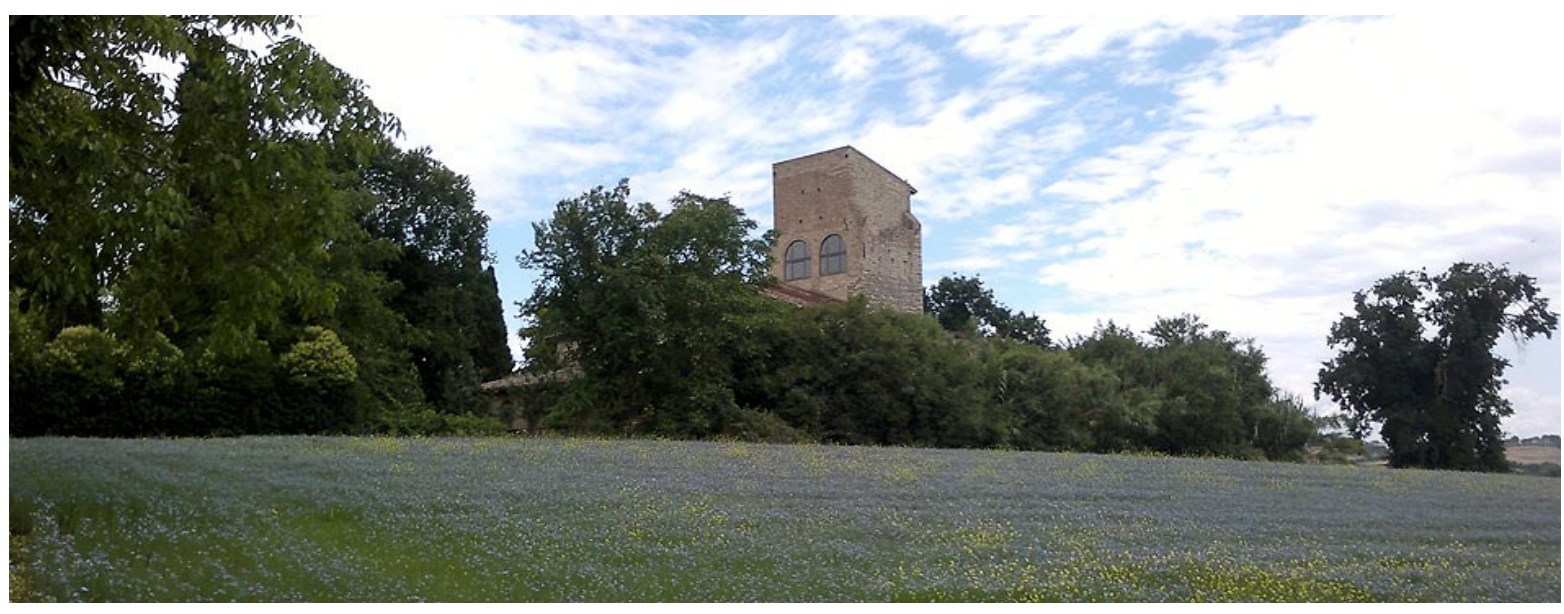

Photo Study Area B: Bosco Sereni and Torricella (photographed by Biancamaria Torquati in 2014)

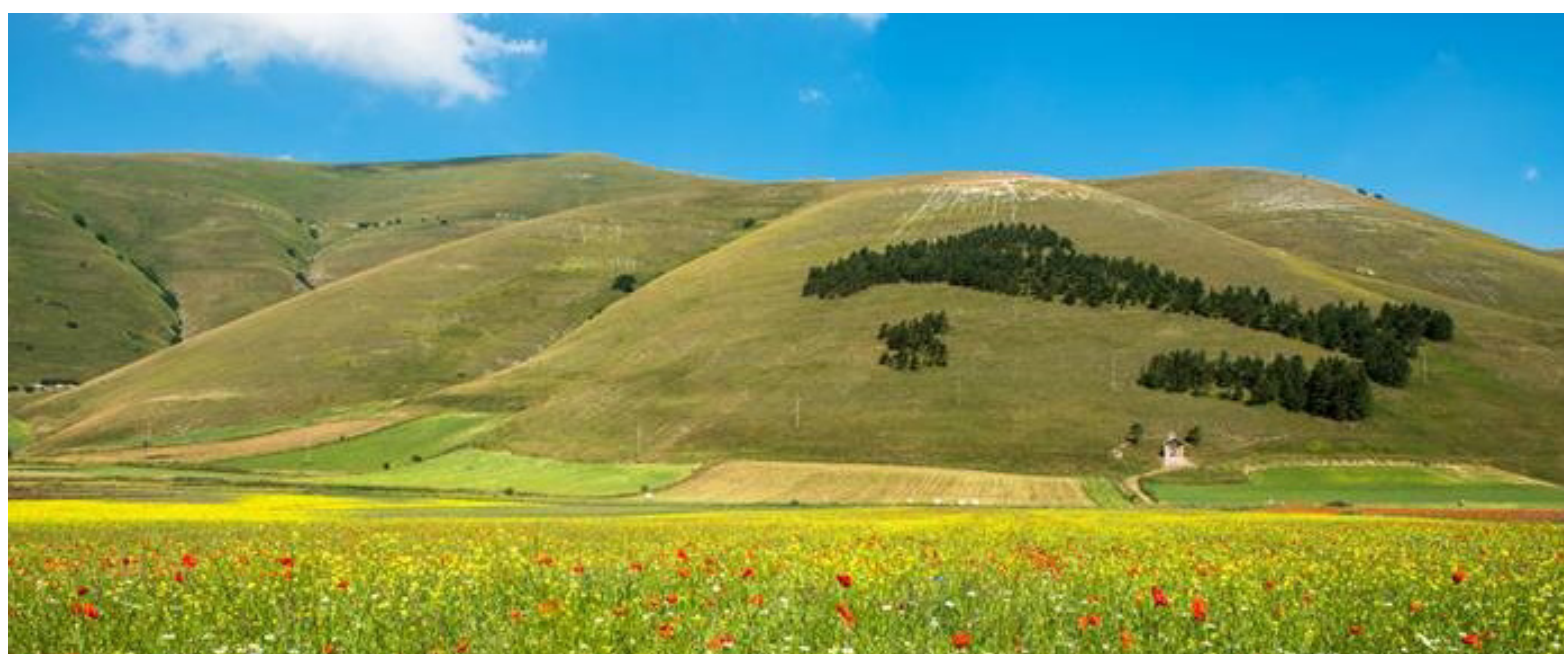

Photo Study Area C: Piani di Castelluccio (http://www.umbriapaesaggio.regione.umbria.it/media/ nursino. „Italia Fiorita“, Castelluccio di Norcia (PG), Istituto Statale G. Galileo, Sant'Eraclio, Foligno, 3A, last access 06.11.2017) 
infrastructure used both for animal husbandry and agricultural activity. The cultivation systems are strongly related to the pedological and orographic features. The area is important for lentil and autumn and spring cereals cultivation. The $\mathrm{SCl}$ offers natureoriented hobbies as well as cultural activities. The "Bosco Sereni" in Torricella covers an overall surface of about 421 hectares and has a predominantly flat morphology with altitudes between 220 and $260 \mathrm{~m}$. S.I.m. including down the Caina and Genna river, in a context that still has a rural structure. From the bioclimatic point of view, the zone can be classified within the temperate bioclimatic region. In this site, woods and meadows coexist, providing a fascinating naturalistic/didactic itinerary. Additionally, a naturalistic museum, which valorises the culture of the place and accustoms visitors on environmental practices, is located in the area. The "Ansa degli Ornari" is an area of 221 hectares and is placed a few miles from the city of Perugia. It is a bight of the Tiber River in the Perugia valley bottom, and it is considered one of the most interesting naturalistic oases of the Central Italy. In the area, predominantly woody hygrophilous species grow. The $\mathrm{SCl}$ is particularly important for the precious wetlands where different species of birds, both nesting and migratory, can rest. In the recent past, river vegetation bands have been reduced mainly due to agricultural activity, and naturalistic and recreational areas have been integrated with surrounding urban areas.

A georeferenced database of the agritourism farms was built, and the final agritourism farms where to collect the choice experiment data were chosen using GIS-processing. 40 agritourism farms were identified, $38 \%$ of which were within the four Nature $2000 \mathrm{SCls}$ selected and $62 \%$ were close by (within a distance of $5 \mathrm{~km}$ measured in a straight line). Consultation of the agritourisms' websites revealed that 28 out 40 were operating: $35 \%$ of these structures were located within the four Nature $2000 \mathrm{SCls}$ selected while $65 \%$ of them were nearby.

\section{Results and Discussion}

\subsection{Sample characteristics}

Table 1 shows a general overview of the sociodemographics characteristics of the interviewees. Of the 160 respondents, 54\% were women, and 52.5\% were between 31 and 40 .

The respondents had a high educational level: $56.3 \%$ hold a master's degree or PhD, while $23.8 \%$ had earned a bachelor's degree. More than $70 \%$ of the sample members were employed, while $6.9 \%$ were retirees and $7.5 \%$ students.

\subsection{Agritourism preferences}

On average, the interviewees had opted for a short break (1-3 nights) and B\&B service, with family or a partner. For the majority, they had searched on the Internet using websites that publish information on agritourism farms, but sometimes they relied on word of mouth.

The reasons indicated for choosing an agritourism holiday involved the wish to escape from the crowd (peace and quiet, 27.7\%) and get back to nature (22.6\%), the opportunity to enjoy wholesome food (18.2\%), the low price of such accommodations (17.3\%), and the less formal relationships (12.3\%).

The motivations underlying the choice of an agritourism holiday included the quality of service (cleanliness, breakfast, etc.), considered as important or highly important by $81 \%$ of the sample, and the location in traditional rural landscape (71\%). Farmhouse conservation, overnight price, availability of trekking or bicycle itineraries, or presence of such natural sites as a park, reserve or $\mathrm{SCl}$, seemed to have a medium degree of importance.

As stated in the methodological section (2.1), the interviewees were grouped into two clusters (Table 2 ) using k-means cluster analysis. As a result, $57.5 \%$ of the respondents belong to cluster 1 , and $42.5 \%$ belong to cluster 2 . 
Table 1: Profile of interviewees

\begin{tabular}{|c|c|c|c|c|c|}
\hline & n. & $\%$ & & n. & $\%$ \\
\hline Gender & & & Family members age & & \\
\hline Female & 86 & 53.8 & children (0-7 years) & 3 & 59.7 \\
\hline Male & 74 & 46.3 & youth (8-14 years) & 1 & 28.1 \\
\hline Age & & & elderly (65 or >) & 7 & 12.3 \\
\hline $20-30$ & 23 & 14.4 & Place of residence & & \\
\hline $31-40$ & 84 & 52.5 & urban area - center & $\begin{array}{l}8 \\
9\end{array}$ & 55.6 \\
\hline $41-50$ & 19 & 11.9 & urban area - periphery & 3 & 21.9 \\
\hline $51-60$ & 22 & 13.8 & rural area - village & $\begin{array}{l}1 \\
8\end{array}$ & 11.3 \\
\hline$>60$ & 12 & 7.5 & rural area - isolated house & $\frac{1}{8}$ & 11.3 \\
\hline Education level & & & Region of origin & & \\
\hline primary school certificate & 1 & 0.6 & North Italy & $\begin{array}{l}5 \\
5\end{array}$ & 34.4 \\
\hline middle school certification & 3 & 1.9 & Central Italy & 8 & 50.6 \\
\hline high school certification & 28 & 17.5 & South Italy & 2 & 12.5 \\
\hline bachelor's degree & 38 & 23.8 & Foreign countries & 4 & 2.5 \\
\hline master's degree or PhD & 90 & 56.3 & Association membership & & \\
\hline Occupation & & & environmental & $\begin{array}{l}2 \\
3\end{array}$ & 16.6 \\
\hline employed & 117 & 73.1 & cultural & $\begin{array}{l}6 \\
2\end{array}$ & 44.6 \\
\hline unemployed & 17 & 10.6 & consumer & 1 & 10.1 \\
\hline retired & 11 & 6.9 & voluntary & 2 & 15.8 \\
\hline housewife & 3 & 1.9 & athletic & $\begin{array}{l}1 \\
8\end{array}$ & 13.1 \\
\hline student & 12 & 7.5 & Income & & \\
\hline Household size & & & low & 8 & 5.0 \\
\hline $1-2$ & 66 & 41.3 & medium low & $\begin{array}{l}5 \\
8\end{array}$ & 36.3 \\
\hline 2-4 & 84 & 52.5 & medium high & 9 & 56.3 \\
\hline 5 and above & 10 & 6.3 & high & 4 & 2.5 \\
\hline
\end{tabular}


Table 2: Average score of the 10 elements to group interviewees into two clusters

\begin{tabular}{|l|l|l|}
\hline & Cluster 1 & Cluster 2 \\
\hline Interviewees number & 92 & 68 \\
\hline Price & 3.60 & 3.65 \\
\hline Service quality (cleanliness, breakfast, etc.) & 4.16 & 4.10 \\
\hline Buildings and appliances care/status & 3.59 & 3.79 \\
\hline Proximity of art places & 3.16 & 3.18 \\
\hline Presence of a well-preserved traditional rural landscape* & 3.65 & 4.26 \\
\hline Absence of urban settlements in the proximity* & 2.82 & 3.62 \\
\hline Presence of nature protection areas* & 2.65 & 4.24 \\
\hline Presence of some services (swimming pool, wellness, etc.) & 2.86 & 2.22 \\
\hline Proximity of bicycle of foot paths* & 2.62 & 4.34 \\
\hline Proximity of leisure places (night clubs, pubs, etc.) & 1.82 & 1.87 \\
\hline * score different with 95\% probability & & \\
\hline
\end{tabular}

When choosing an agritourism attribute, the interviewees belonging to cluster 2 consider the presence of protected natural areas, well-preserved traditional rural landscapes, and bicycle paths and walkable itinerary, and the absence of urban settlements, as the most noteworthy features.

Respondents belonging to cluster 2 can generally be considered to search for the opportunity to spend time in touch with a natural or a traditional rural landscape setting during their agritourism vacation. Conversely, people belonging to cluster 1 give more importance to the presence of pools.

\subsection{Choice experiment results}

The DCE estimated model has a good interpretative capacity (McFadden Pseudo R-squared: 0.29) according to the standards of these models (Hensher et al. 2005). All estimated parameters (Table 3) proved significant at the $95 \%$ level, except for the coefficients of three interaction terms $(p<0.10)$ (low village distance $x$ graduate; $\mathrm{SCl} x$ cluster 2 ; swimming pool $x$ graduate).
The WTP for a double room per night was significantly influenced by the individual characteristics of respondents considered in the econometric model as interactions.

DCE results show that the greatest contribution to respondents' utility is given by the presence of a highquality rural landscape, followed by the presence of a swimming pool, the proximity to a historical village and, the location in a $\mathrm{SCl}$ area. The number of spikes was the least important attribute.

Considering that the average actual price for an overnight stay in a generic agritourism is $70 € /$ night for two people, the estimates show that there is a rather high average WTP to stay in an agritourism characterised by a high quality of rural landscape (32.32€/night for two people) (Table 4). The prices people were willing to pay for the availability of a swimming pool (20.95€/night for two people) and the location of the agritourism at less than $3 \mathrm{~km}$ from a historical village (18.37€/night for two people) was of a lower magnitude, albeit not less important. 
Table 3: RPL model with socio-economic interactions results

\begin{tabular}{|c|c|c|c|c|c|c|c|}
\hline & \multirow[t]{2}{*}{ Coeff. } & \multirow[t]{2}{*}{ Std. Error } & \multirow[t]{2}{*}{ t-value } & \multirow[t]{2}{*}{$p$-value } & \multirow{2}{*}{$\begin{array}{l}\text { WTP } \\
\text { average }\end{array}$} & \multicolumn{2}{|c|}{ WTP C.I. (95\%) } \\
\hline & & & & & & Inf. & Sup. \\
\hline \multicolumn{8}{|c|}{ Random parameters (latent heterogeneity) } \\
\hline Low village distance & 0.9283 & 0.3350 & 2.7710 & 0.0056 & 18.37 & 5.46 & 31.27 \\
\hline $\mathrm{SCl}$ & 0.6860 & 0.1951 & 3.5170 & 0.0004 & 13.57 & 6.37 & 20.77 \\
\hline Swimming pool & 1.0590 & 0.3585 & 2.9540 & 0.0031 & 20.95 & 7.15 & 34.76 \\
\hline High quality landscape & 1.6334 & 0.1568 & 10.4170 & 0.0000 & 32.32 & 26.26 & 38.37 \\
\hline Spikes 5 & 0.4359 & 0.1221 & 3.5710 & 0.0004 & 8.62 & 3.85 & 13.40 \\
\hline \multicolumn{8}{|l|}{ Non-Random Parameters } \\
\hline \multirow[t]{2}{*}{ Opt-out } & - & 0.2963 & -9.5700 & 0.0000 & & & \\
\hline & 2.8356 & & & & & & \\
\hline \multirow[t]{2}{*}{ Price } & & 0.0036 & -13.8590 & 0.0000 & & & \\
\hline & 0.0505 & & & & & & \\
\hline \multicolumn{8}{|c|}{ Heterogeneity in mean parameter: Variable } \\
\hline \multirow[t]{2}{*}{ Low village distance $\mathrm{x}$ cluster 2} & - & 0.2836 & -2.7740 & 0.0055 & -15.57 & -26.58 & -4.55 \\
\hline & 0.7867 & & & & & & \\
\hline \multirow[t]{2}{*}{ Low village distance $x$ graduate } & - & 0.3339 & -1.9110 & 0.0561 & -12.62 & -25.56 & 0.32 \\
\hline & 0.6380 & & & & & & \\
\hline $\mathrm{SCl} \times$ income medium-high & 0.5334 & 0.1928 & 2.7660 & 0.0057 & 10.55 & 3.08 & 18.02 \\
\hline $\mathrm{SCl} \times$ cluster 2 & 0.3384 & 0.1956 & 1.7300 & 0.0837 & 6.69 & -0.94 & 14.33 \\
\hline Swimming pool $\mathrm{x}$ age below 30 & 0.9893 & 0.3906 & 2.5330 & 0.0113 & 19.57 & 4.43 & 34.71 \\
\hline \multirow[t]{2}{*}{ Swimming pool $\mathrm{x}$ cluster 2} & & 0.2771 & -2.9680 & 0.0030 & -16.27 & -27.02 & -5.52 \\
\hline & 0.8225 & & & & & & \\
\hline Swimming pool $x$ graduate & 0.6673 & 0.3435 & 1.9430 & 0.0521 & 13.20 & -0.16 & 26.56 \\
\hline \multicolumn{8}{|c|}{ Standard deviations of random parameters distributions } \\
\hline Low village distance & 1.1061 & 0.1707 & 6.4780 & 0.0000 & & & \\
\hline $\mathrm{SCl}$ & 0.5270 & 0.1646 & 3.2030 & 0.0014 & & & \\
\hline Swimming pool & 1.2119 & 0.1596 & 7.5950 & 0.0000 & & & \\
\hline High quality landscape & 0.9835 & 0.1693 & 5.8090 & 0.0000 & & & \\
\hline Spikes 5 & 0.0351 & 0.3991 & 0.0880 & 0.9299 & & & \\
\hline N. Observations $=1,280$ & \multicolumn{7}{|c|}{ Loglikelihood =-1,406.224 } \\
\hline McFadden pseudo R-squared $=0.2844$ & \multicolumn{7}{|c|}{ Halton draws $=1,000$} \\
\hline
\end{tabular}

Table 4: WTP estimates for each attribute considering individual characteristics

\begin{tabular}{|c|c|c|c|c|c|}
\hline \multirow[t]{2}{*}{ Attribute } & \multicolumn{5}{|c|}{ WTP* } \\
\hline & Base value & Cluster 2 & Graduate & $\begin{array}{c}\text { Income } \\
\text { medium- high } \\
\text { or high }\end{array}$ & $\begin{array}{l}\text { Age lower or } \\
\text { equal to } 30\end{array}$ \\
\hline Low village distance & 18.37 & 2.80 & 5.74 & & \\
\hline $\mathrm{SCl}$ & 13.57 & 20.27 & & 24.12 & \\
\hline Swimming pool & 20.95 & 16.04 & 34.15 & & 40.52 \\
\hline High quality landscape & 32.32 & & & & \\
\hline Spikes 5 & 8.62 & & & & \\
\hline
\end{tabular}


The WTP for an agritourism that has five spikes instead of three was much lower (8.62€/night for two people).

However, personal characteristics and preferences influence these figures. In this respect, the most important individual element is the cluster of belonging. People belonging to cluster 2 are willing to pay more for the proximity to a $\mathrm{SCl}(20.27 € /$ night for two people) than for the presence of a swimming pool (16.04€/night for two people) and the proximity to a historical village (2.80€/night for two people). Additionally, the graduates' respondents do not seem to appreciate the closeness to an historical village (WTP $=5.74 € /$ night for two people) but, at the same time, they attribute the highest importance to the presence of a swimming pool (WTP $=34.15 € /$ night for two people). In general, younger interviewees place most attention on the presence of a swimming pool (WTP $=40.52 € /$ night for two people).

Finally, respondents with a high or a medium-high income are willing to pay on average an added amount of $24.12 € /$ night for two people for an agritourism farm placed in a $\mathrm{SCl}$, confirming the finding in Santeramo and Barbieri (2016) where the agriturism demand depend on the agritourist income. The average WTP for an attribute is only partially useful for the implementation of a marketing strategy by agritourism entrepreneurs. In fact, it does not correspond to the real premium price that the owners can earn, since, from a market perspective, it corresponds to the premium price that $50 \%$ of agritourists are willing to pay when an attribute is considered normally distributed. To design an effective marketing strategy, the agritourism entrepreneurs should consider the inverse relationship existing between the number of overnight stays and the price of accommodation. In this respect, it is useful to analyse the complementary cumulative frequencies of the WTP, which show the fraction of the interviewees WTP a given premium price for any level of an attribute.

Figure 3 indicates that approximately $90 \%$ of respondents have a positive WTP for the availability of swimming pool and only $50 \%$ are willing to pay a premium to stay in an agritourism far less than $3 \mathrm{~km}$ from a historical village.

Conversely, $100 \%$ are willing to pay more to be in an agritourism placed in a $\mathrm{SCl}$ or surrounded by a well-preserved traditional rural landscape. It is also worth noting that the lower WTP is 7.6€ for a double room per night for an agritourism situated in a $\mathrm{SCl}$ and $2.3 €$ for an agritourism located in a high-quality landscape.

Figure 3 shows that it is, therefore, possible to study the best pricing policy for the attributes considered to reach the targeted population. For example, in a high-quality traditional rural landscape, if the price of the overnight stays increased by $17 €$, there will be a demand reduction of $10 \%$. In a $\mathrm{SCl}$, the same reduction will happen if the price for staying increased by 12 .

\section{Conclusions}

$T$ his study highlighted how traditional rural landscape and environmental quality play a significant role in agritourism promotion in the rural areas. Ceteris paribus, tourists tend to choose as a holiday destination agritourism farms placed in wellpreserved traditional agricultural landscapes and in $\mathrm{SCls}$ that offer the preservation of biodiversity and opportunities for outdoor sports, cultural activities and naturalistic itinerary.

The results show that tourists pay attention to the sustainability of the service they acquire and to its "cultural" content (local cultural based facilities), as seen, respectively, in the positive WTPs expressed on the high-quality landscape, $\mathrm{SCl}$ and low village distance attributes. These results confirmed what the few international studies evidenced applying the revealed preference methods (Fleischer \& Tchetchik 2005; Fleischer \& Tsur 2000; Vanslembrouck et al. 2005). In fact, as mentioned above, no studies have been conducted applying this method across Italian agritourism sector. 


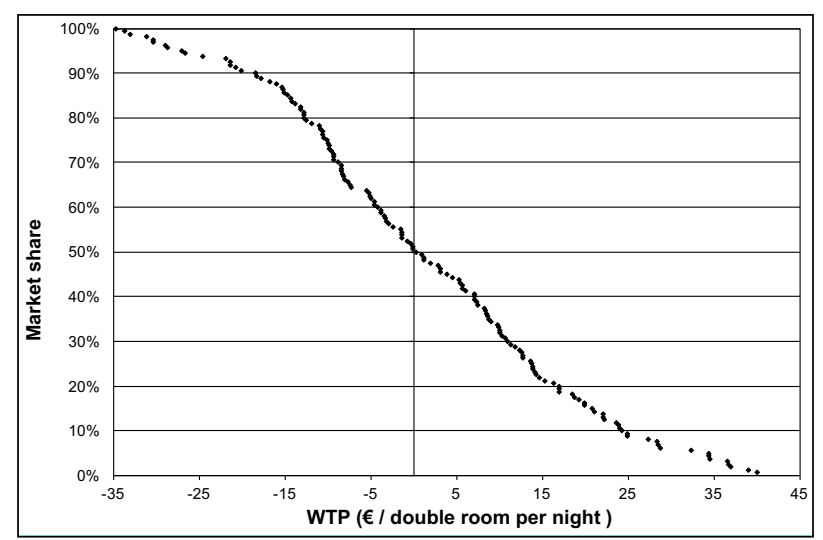

Agritourism distance from a historical village lower than $3 \mathbf{~ k m}$

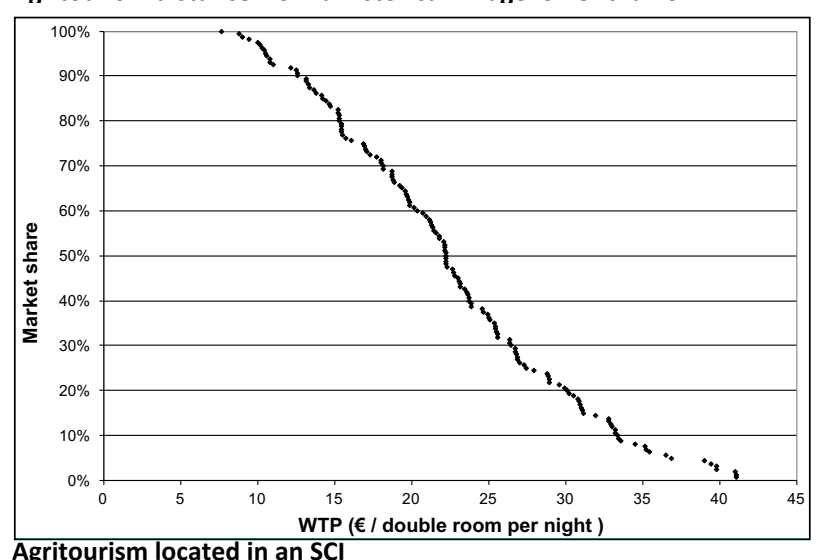

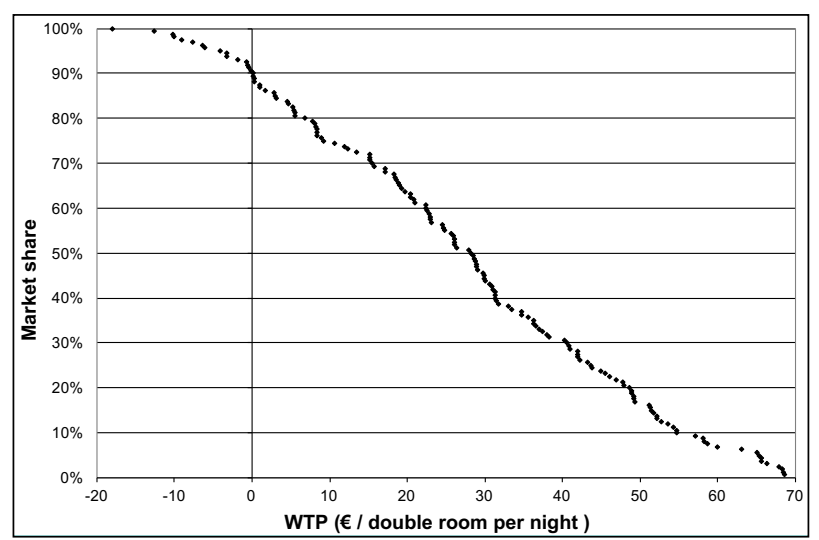

Presence of a swimming pool

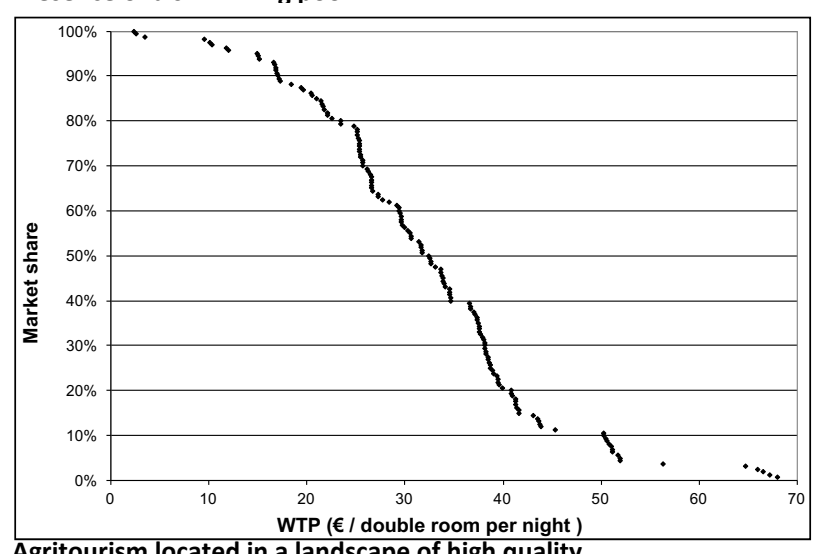

Figure 3: Complementary cumulative frequencies of the individual WTPs

Positive WTP has been estimated for facility-based services: swimming pool and number of spikes as a proxy for overall hospitality quality. In particular, the WTP for the presence of swimming pool is high. This estimate confirms that the availability of a swimming pool has a strong influence on the price when choosing an agritourism across Italy (Ohe \& Ciani, 2011).

Although Ohe and Ciani (2011) have underlined that the facility based services influenced the price of agritourism more than local cultural based, the study results have well-satisfied both type of services.

Our results are crucial for understanding the importance in monetary terms of landscape quality and the presence of $\mathrm{SCl}$ areas in driving consumer demand for agritourism hospitality.

One important aspect highlighted is the mutually beneficial relationship between agritourism services and preservation of traditional rural landscape and biodiversity. Even considering the lower limit value of the confidence interval of the WTP estimates, the premium price our respondents were willing to pay for a holiday in a traditional rural landscape varied on average between $26 €$ and $38 €$ for two persons per night. This amount could be considered relevant if compared with the average cost (70€) of staying in a generic agritourism in the Umbria Region and could offer to agritourism entrepreneurs an important indicator for formulating a premium price. In this respect, owners of agritourism farms have a strong incentive for preserving the traditional rural landscape around their property, thus improving the sustainability of their farming activity.

From the tourism perspective, the overall results confirm that nature conservation, landscape management and their sustainable use are relevant according to the results obtained by Bastian et al. (2015) and Carpio et al. (2008). Bastian et al. (2015) had already estimated a WTP between $1.06 €$ and $2.73 €$ per day for visitors in the Eastern Ore Mountains (Saxony, Germany). Carpio et al. (2008) estimated a consumer surplus for rural landscape of $\$ 33.50$ for 
American farm visitors. The two different results are attributable also to the different measurements and methods of analysis used by the authors (stated preferences valuation in the first case and reveled prefences valuation in the second one), but mostly to visitors' determinants in so very different places. The positive externalities generated by Natura 2000 $\mathrm{SCls}$ can be considered significant, although to a lesser degree compared to the positive externalities produced by traditional rural landscape.

The results show how the conservation of nature could have consistent positive repercussions for economic activities in rural areas, but increased awareness and knowledge of the benefits related to other features like Natura 2000 sites is still needed as suggested also by Gao et al. 2014 and by Santeramo and Barbieri, 2016.

The results of the study suggest that the public support for preservation programs might also be linked to the benefits obtained by tourists from the scenic attractiveness of the rural landscape from working farms.

Additionally, concerning possible EU policies for rural development, a certification procedure for traditional rural landscape quality could be established. For example, Italy's Government is developing such a certification, in the form of a National Registry of Historical Landscapes. It could be an important marketing instrument, both for agritourism entrepreneurs using certification in their advertising and for keeping tourists informed about destinations where the historical and cultural values of the landscape are protected.

It should be noted that agritourism farms that are not included would struggle in providing landscape conservation services in the major geographic areas. The influx of tourists attracted by agritourism farms and tourism, in general, could greatly benefit the sale of local agricultural products. Nevertheless, given that landscape is a pure public good, some farmers could adopt farming practices that increase production costs, but with substantial impacts on the traditional rural landscape as a side effect. To avoid the latter scenario, rural and touristic regulations should attempt to coordinate the local stakeholders and give them incentives for collaborative behaviour, including policies that remunerate farmers for their role in conserving the quality of the traditional, sustainable landscape.

Landscape and environmental quality of rural area are largely the results of the farmers' work. Hence, there cannot be a question in doing simple passive protection and conservation policies. It is necessary to make effective policies related to the farm profitability and competitiveness that can find proper forms of productive resources management and incentives distribution.

Therefore, more studies are needed as well as different and advanced research methods to overpass the gap between landscape and nature evaluation and practical decision making (Carpio et al. 2008). From this perspective, agritourism has a significant role in developing resources in terms of dynamic conservation, competitiveness and farmer income.\#

\section{Acknowledgements}

$T$ he research on which this paper is based was undertaken as part of a research project "Traditional agricultural landscapes in Italy: multidisciplinary and multi-scale assessment for the development of an integrated model for landscape planning and management" co-financed by Programs of Relevant National Interest (Prin) Grant number 2010LE4NBM_013.

\section{References}

Adhikari, A. 2015. Differentiating subjective and objective attributes of experience products to estimate willingness to pay price premium. Journal of Travel Research 54(5), 634-644. 
Agnoletti, M. (eds) 2013. Italian historical rural landscapes: cultural values for the environment and rural development (Vol. 1). Springer Science \& Business Media.

Albaladejo-Pina, I. P.\& Díaz-Delfa, M. T. 2009. Tourist preferences for rural house stays: Evidence from discrete choice modelling in Spain. Tourism Management 30(6), 805-811.

Antrop, M. 2005. Why landscapes of the past are important for the future. Landscape and urban planning 70(1), 21-34.

Apostolakis, A. \& Jaffry, S. 2005. A choice modeling application for Greek heritage attractions. Journal of travel research 43(3), 309-318.

Barbieri, C. \& Mshenga, P. M. 2008. The role of the firm and owner characteristics on the performance of agritourism farms. Sociologia ruralis 48(2), 166183.

Barros, C. P.; Butler, R. \& Correia A. 2008. Heterogeneity in destination choice tourism in Africa. Journal of Travel Research 47(2), 235-246.

Bastian, O.; Stein, C; Lupp, G; Behrens, J; Renner, C; Grunewald, K. 2015. The appreciation of nature and landscape by tourism service providers and visitors in the Ore Mountains (Germany). Landscape Online 41:1-23, DOI 10.3097/ LO.201541

Bel, F.; Lacroix, A.; Lyser, S.; Rambonilaza, T. \& Turpin, N. 2015. Domestic demand for tourism in rural areas: Insights from summer stays in three French regions. Tourism Management 46, 562-570.

Brau, R. 2008. Demand-driven sustainable tourism? A choice modelling analysis. Tourism Economics 14(4), 691-708.

Busby, G. \& Rendle, S. 2000. The transition from tourism on farms to farm tourism. Tourism management 21(6), 635-642.

Capriello, A.; Mason, P. R.; Davis, B. \& Crotts, J. C. 2013. Farm tourism experiences in travel reviews: A cross-comparison of three alternative methods for data analysis. Journal of Business Research 66(6), 778-785.
Carpio, C. E.; Wohlgenant, M. K. \& Boonsaeng, T. 2008. The demand for agritourism in the United States. Journal of Agricultural and Resource Economics 33(2), 254-269.

Choi, A. S.; Ritchie, B. W.; Papandrea, F. \& Bennett, J. 2010. Economic valuation of cultural heritage sites: A choice modeling approach. Tourism Management 31(2), 213-220.

Claval, P. 2005. Reading the rural landscapes. Landscape and Urban Planning 70(1), 9-19.

Contini, C.; Scarpellini, P. \& Polidori, R. 2009. Agritourism and rural development: The Low-Valdelsa case, Italy. Tourism Review 64(4), 27-36.

Crouch, G. I. \& Louviere, J. J. 2000. A review of choice modeling research in tourism, hospitality, and leisure. Tourism Analysis 5(2/4), 97-104.

Devesa, M.; Laguna, M. \& Palacios, A. 2010. The role of motivation in visitor satisfaction: Empirical evidence in rural tourism. Tourism management 31(4), 547-552.

Flanigan, S.; Blackstock, K. \& Hunter, C. 2015. Generating public and private benefits through understanding what drives different types of agritourism. Journal of Rural Studies 41, 129-141.

Fleischer, A. \& Tchetchik, A. 2005. Does rural tourism benefit from agriculture? Tourism Management 26(4), 493-501.

Fleischer, A. \& Tsur, Y. 2000. Measuring the recreational value of agricultural landscape. European Review of Agricultural Economics 27(3), 385-398.

Gantioler, S.; Rayment, M.; ten Brink, P.; McConville, A.; Kettunen, M. \& Bassi, S. 2014. The costs and socio-economic benefits associated with the Natura 2000 network. International Journal of Sustainable Society 6(1-2), 135-157.

Gao, J.; Barbieri, C. \& Valdivia, C. 2014. Agricultural landscape preferences: Implications for agritourism development. Journal of Travel Research 53(3), 366-379.

Hedlund, T. 2013. Tourists' vacation choice structure: Influence of values and implications for green tourism. (Doctoral dissertation, Umeå Universitet) 
Hensher, D. A., Rose, J. M. \& Greene, W. H., 2005. Applied choice analysis: a primer. Cambridge University Press.

Hensher, D. A. \& Greene, W. H. 2003. The mixed logit model: the state of practice. Transportation 30(2), 133-176.

Hole, A. R. \& Kolstad, J. R. 2012. Mixed logit estimation of willingness to pay distributions: a comparison of models in preference and WTP space using data from a health-related choice experiment. Empirical Economics 42(2), 445-469.

Howley, P.; Donoghue, C. O. \& Hynes, S. 2012. Exploring public preferences for traditional farming landscapes. Landscape and Urban Planning 104(1), 66-74.

Huybers, T. \& Bennett, J. 2003. Environmental management and the competitiveness of naturebased tourism destinations. Environmental and Resource Economics 24(3), 213-233.

ISTAT. 2014. The agritourism in Italy (Le aziende agrituristiche in Italia), Rome: ISTAT. http://www. ISTAT.it/it/archivio/133966. (Date:10.07.2015).

Juutinen, A.; Mitani, Y.; Mäntymaa, E.; Shoji, Y.; Siikamäki, P. \& Svento, R. 2011. Combining ecological and recreational aspects in national park management: A choice experiment application. Ecological Economics 70(6), 12311239.

Kelly, J.; Haider, W.; Williams, P. W. \& Englund, K. 2007. Stated preferences of tourists for ecoefficient destination planning options. Tourism Management 28(2), 377-390.

Kim, S. S. \& Lee, C. K. 2002. Push and pull relationships. Annals of Tourism Research 29(1), 257-260.

Koutsouris, A.; Gidarakou, I.; Grava, F. \& Michailidis, A. 2014. The phantom of (agri) tourism and agriculture symbiosis? A Greek case study. Tourism Management Perspectives 12, 94-103.

LaPan, C. \& Barbieri, C. 2014. The role of agritourism in heritage preservation. Current Issues in Tourism 17(8), 666-673.
Lancaster, K. J. 1966. A new approach to consumer theory. Journal of Political Economy 74(2), 132157.

Law 20 February 2006, n. 96: „Disciplina dell'agriturismo“, Gazette n. 6316 March 2006.

Leco, F.; Hernández, J. M. \& Campón, A. M. 2013. Rural tourists and their attitudes and motivations towards the practice of environmental activities such as agritourism. International Journal of Environmental Research 7(1), 255-264.

Lee, C. K.; Lee, J. H.; Kim, T. K. \& Mjelde, J. W. 2010. Preferences and willingness to pay for birdwatching tour and interpretive services using a choice experiment. Journal of Sustainable Tourism 18(5), 695-708.

Lim, Y. \& Weaver, P. A. 2014. Customer-based Brand Equity for a Destination: The effect of destination image on preference for products associated with a destination brand. International Journal of Tourism Research 16(3), 223-231.

Lindberg, K. \& Veisten, K. 2012. Local and nonlocal preferences for nature tourism facility development. Tourism Management Perspectives 4, 215-222.

Macagno, G.; Loureiro, M. L.; Nunes, P. A. \& Tol, R. S. 2009. Assessing the impact of biodiversity on tourism flows: a model for tourist behaviour and its policy implications (Available at SSRN: http:// ssrn.com/abstract=1424982 or http://dx.doi. org/10.2139/ssrn.1424982) (Date: 10.10.2014).

Macagno, G.; Nunes, P. A. \& Loureiro, M. 2010. The influence of agriculture landscape on tourism flows: An application for Tuscany (Available at http://www.bioecon-network. org/pages/12th_2010/Macagno.pdf) (Date: 16.10.2014).

McFadden, D. 1974. The measurement of urban travel demand. Journal of Public Economics 3(4), 303-328.

Ohe, Y. \& Ciani, A. 2011. Evaluation of agritourism activity in Italy: Facility based or local culture based? Tourism Economics 17(3), 581-601. 
Ohe, Y. \& Ciani, A. 2012. Accessing demand characteristics of agritourism in Italy. Tourism and Hospitality Management 18(2), 281-296.

Ohe, Y. \& Kurihara, S. 2013. Evaluating the complementary relationship between local brand farm products and rural tourism: Evidence from Japan. Tourism Management 35, 278-283.

Paracchini, M. L., Correia, T. P., Loupa-Ramos, I., Capitani, C. \& Madeira, L. 2016. Progress in indicators to assess agricultural landscape valuation: how and what is measured at different levels of governance. Land Use Policy 53, 71-85.

Park, D. B. \& Yoon, Y. S. 2009. Segmentation by motivation in rural tourism: A Korean case study. Tourism Management 30(1), 99-108.

Randelli, F., Romei, P. \& Tortora, M. 2014. An evolutionary approach to the study of rural tourism: The case of Tuscany. Land Use Policy 38, 276-281.

Regional Law n. 28/1997, Umbria Region, „Disciplina delle attività agrituristiche“. B.U.R. 20/08/1997, n.39.

Santeramo, F. G. \& Barbieri, C. 2016. On the demand for agritourism: a cursory review of methodologies and practice. Tourism Planning \& Development 14(1), 139-148.

Santeramo, F. G. 2015. Promoting the international demand for agritourism: empirical evidence from dynamic panel data model. Tourism Economics 21(4), 907-916.

Santeramo, F. G., \& Morelli, M. 2014. Enhancing the foreign demand for rural tourism. Politica Agricola Internazionale 2, 33-42.

Santucci, F. M. 2013. Agritourism for rural development in Italy, Evolution, Situation and Perspectives. Development 15, 16.

Schilling, B. J., Attavanich, W. \& Jin, Y. 2014. Does agritourism enhance farm profitability. Journal of Agricultural and Resource Economics 39(1), 6987.

Sidali, K. L. \& Schulze, B. 2010. Current and future trends in consumers' preference for farm tourism in Germany. Leisure/Loisir 34(2), 207-222.
Skuras, D.; Petrou, A. \& Clark, G. 2006. Demand for rural tourism: the effects of quality and information. Agricultural Economics 35(2), 183192.

Slee, B.; Farr, H. \& Snowdon, P. 1997. The economic impact of alternative types of rural tourism. Journal of agricultural economics 48(1-3), 179192.

Tew, C. \& Barbieri, C. 2012. The perceived benefits of agritourism: The provider's perspective. Tourism Management 33(1), 215-224.

Torquati, B.; Giacchè, G. \& Venanzi, S. 2015. Economic analysis of the traditional cultural vineyard landscapes in Italy. Journal of Rural Studies 39, 122-132.

Train, K. \& Weeks, M. 2005. Discrete choice models in preference space and willingness-to pay space. Applications of simulation methods in environmental and resource economics 1-16.

Train, K. 2003. Discrete choice methods with simulation. Cambridge university press.

Vanslembrouck, I.; Huylenbroeck, G. \& Meensel, J. V. 2005. Impact of agriculture on rural tourism: a hedonic pricing approach. Journal of Agricultural Economics 56(1), 17-30.

Walford, N. 2001. Patterns of development in tourist accommodation enterprises on farms in England and Wales. Applied Geography 21(4), 331-345.

Yadav, L. P.; O’Neill, S. \& Van Rensburg, T. 2013. Supporting the conservation of farm landscapes via the tourism sector. The Economic and Social Review 44(2), 221-245.

Yoon, Y. \& Uysal, M. 2005. An examination of the effects of motivation and satisfaction on destination loyalty: a structural model. Tourism Management 26(1), 45-56. 